\title{
KẾT QUẢ ĐIỀU TRI CHẢY MÁU DƯỚI NHỆN DO VÕ̃ PHÌNH ĐộNG MẠCH VÕ̃ TẠI BỆNH VIỆN VIỆT ĐỨC
}

\section{TÓM TẮT}

Muc tiêu: đánh giá kết quả điều trị chảy máu dưới nhện do phình mạch vỡ. Đối tượng và phương pháp nghiên cứu: Nghiên cứu hồi cứu 47 bệnh nhân được chẩn đoán và điều trị chảy máu dưới nhện do phình mach võ tai bênh viện Viêt Đức từ 6.2019 đén 9.2020. Kết quả: tuổi trung bình của bệnh nhân 46,4; nam giới: 42,55\%; đau đầu, buồn nôn, liệt nửa người là các triệu chứng thườn gặp với tỉ lệ $100 \%$, $85,1 \%$ và $36,17 \%$ tương ứng. $12,77 \%$ số bênh nhân có đa túi phình; kết quả cải thiện rõ rệt 3 tháng sau điều trị. Kết luân: Điều trị chảy máu dưới nhện do phình mạch vỡ vẫn còn là một chủ đề phức tạp, dù đã có nhiều hiểu biết và tiến bộ.

\section{SUMMARY}

\section{THE RESULTS OF ANEURYSMAL SUBARACHNOIDAL HEMORRHAGE AT VIET-DUC HOSPITAL}

Objective: assessment of the results of aneurysmal subarachnoidal hemorrhage. Patients and methods: A retrospective study with 47 patients diagnosed and treated with aneurysmal subarachnoidal hemorrhage at Viet-Duc hospital from June 2019 to September 2020. Results: patient's mean age: 46,1; male (42,55\%); headache, nausea/vomit, hemiparesis were the most common symptoms (100\%, $85.1 \% ; 36.17 \%$, respective). Multiple aneurysms account for $12.77 \%$ of patients; the clinical result (with $\mathrm{mRS}$ ) significantly improved at three months-follow. Conclusion: The management of aneurysmal subarachnoidal hemorrhage is a complex undertaking, and the current state of knowledge is in rapid evolution

\section{I. ĐĂT VẤN ĐỀ}

Chảy máu khoang dưới nhện là tình trạng thường gặp trong võ phình động mạch não [1], là tình trạng có thể đe doạ tính mạng của bênh nhân. Chảy máu khoang dưới nhện thường để lại nhiều hậu quả, ngay cả khi nguyên nhân của nó là các túi phình động mạch não đã được điều trị [2]. Điều trị chảy máu dưới nhện bao gồm phẫu thuật làm sạch máu ở khoang dưới nhện kết hợp với điều trị xử lý túi phình động mạch não hoặc điều trị nội khoa với các trường hợp phình động

${ }^{1}$ Bệnh viện Việt Đức

2Đai hoc Y Hà nọi

Chịu trách nhiệm chính: Ngô Mạnh Hùng

Email: ngomanhhung2000@gmail.com

Ngày nhận bài: 4.2.2021

Ngày phản biên khoa hoc: 15.3.2021

Ngày duyệt bài: 30.3.2021

\section{Ngô Mạnh Hùng1, Nguyễn Đức Nghĩa ${ }^{2}$}

mạch não được can thiệp nội mạch. Nghiên cứu này nhằm đánh giá kết quả điều trị chảy máu dưới màng nhện do võ̃ phình động mạch não ở bệnh viện Việt Đức từ 6.2019 đến 9.2020.

\section{II. ĐỐI TƯỢNG VÀ PHƯƠNG PHÁP NGHIÊN CỨU}

Nghiên cứu được tiến hành tại bệnh viện Việt Đức trong thời gian từ 6.2019 đển 9.2020.

\section{Tiêu chuẩn lựa chọn bệnh nhân}

- Bệnh nhân có chẩn đoán là chảy máu khoang dưới nhện trên phim chụp CT sọ não không tiêm thuốc

- Bệnh nhân được chẩn đoán phình động mạch não võ, bởi phim cắt lớp vi tính dựng hình mạch não (CTA) hoặc phim chụp động mạch não số hoá xoá nền (DSA).

- Bệnh nhân có đầy đủ hồ sơ bệnh án

- Bệnh nhân được khám lại điều trị 3 tháng

\section{Tiêu chuấn loại trừ}

- Bệnh nhân được chẩn đoán chảy máu khoang dưới nhện nhưng không có ít nhất một trong các tiêu chuẩn trên.

\section{Các biến số nghiên cứu}

- Tuổi, giới, thời gian từ khi đột quy. đến khi vào viện, phân loại chảy máu dưới màng nhện theo thang điểm Fisher cải tiến[3], vị trí động mạch nuôi của phình động mạch não

- Kết cục điêu trị khi ra viện: tình trạng khi vào viện, khi ra viên và kết quả điểu trị sau 3 tháng theo thang điểm Rankin cải tiến (modified Rankin Scale: $\mathrm{mRS}$ )

Số liệu được thu thập, làm sạch, xử lý theo các thuật toán thống kề thông thường với phần mềm SPSS 20.0.

\section{KẾT QUẢ NGHIÊN CỨU}

Trong thời gian từ 6.2019 đến 9.2020, tại trung tâm phẫu thuật Thần kinh, bệnh viện Việt Đức, chúng tôi đã có 47 bệnh nhân được chẩn đoán chảy máu khoang dưới nhên (SAH: subarachnoidal hemorrhage) do võ phình động mạch não.

Bảng 1. Đặc đîểm chung của nhóm bệnh nhân

\begin{tabular}{|c|c|c|c|}
\hline $\begin{array}{l}\text { Đặc điếm nhóm } \\
\text { bệnh nhân }\end{array}$ & $\begin{array}{l}\text { Số } \\
\text { lượng }\end{array}$ & Tỉ lệ \% & $\mathbf{P}$ \\
\hline Nam & 10 & 42,55 & 0,43 \\
\hline Tuổi trung bình & $\begin{array}{l}46,4 \pm \\
13,26\end{array}$ & $\begin{array}{l}\text { Nhỏ nhấ } \\
\text { Lớn nhấ }\end{array}$ & $\begin{array}{l}\text { ất: } 3 ; \\
\text { ất: } 74\end{array}$ \\
\hline $\begin{array}{c}\text { Thời gian từ khi có đột } \\
\text { quy-chẩn đoán (h) }\end{array}$ & $\begin{array}{c}16,95 \pm \\
12,49\end{array}$ & $\begin{array}{l}\text { Nhỏ nhấ } \\
\text { Lớn nhấ }\end{array}$ & $\begin{array}{l}\text { ất: } 3 ; \\
\text { ât: } 48\end{array}$ \\
\hline
\end{tabular}


VIETNAM MEDICAL JOURNAL N01 - APRIL - 2021

\begin{tabular}{|c|c|c|c|}
\hline \multicolumn{4}{|c|}{ Triệu chứng lâm sàng } \\
\hline Đau đầu & 47 & \multicolumn{2}{|c|}{100} \\
\hline Buồn nôn/nôn & 40 & \multicolumn{2}{|c|}{85,1} \\
\hline Liệt nửa người & 17 & \multicolumn{2}{|c|}{36,17} \\
\hline Thất ngô̂n & 8 & \multicolumn{2}{|c|}{17,02} \\
\hline \multicolumn{4}{|c|}{ Thang điếm Glassgow } \\
\hline $3-8$ & 7 & 14,90 & \multirow{3}{*}{0,03} \\
\hline $9-12$ & 35 & 76,46 & \\
\hline $13-15$ & 5 & 10,64 & \\
\hline \multicolumn{4}{|c|}{ Số lượng túi phình } \\
\hline 1 túi phình & 41 & 87,23 & \\
\hline Đa túi phình $(\geq 2)$ & 6 & 12,77 & \\
\hline
\end{tabular}

Bảng 2. Phân bố mức đô chảy máu dưới màng nhện theo thang điểm Fisher cải tiến \begin{tabular}{|l|l|l|}
\hline Thang điếm Fisher cải & Số lệ
\end{tabular}

\begin{tabular}{|c|c|c|}
\hline tiến & lượng & $\%$ \\
\hline Độ 0 & 0 & 0 \\
\hline Độ 1 & 16 & 34,04 \\
\hline Độ 2 & 21 & 44,68 \\
\hline Đồ 3 & 7 & 14,89 \\
\hline Độ 4 & 3 & 6,39 \\
\hline Tống số & 47 & 100 \\
\hline
\end{tabular}

Bảng 3. Phân bố bệnh nhân theo vị trí phinh động mạch não võ

\begin{tabular}{|c|c|c|}
\hline Vị trí động mạch nuôi & $\begin{array}{c}\text { Số } \\
\text { Iượng }\end{array}$ & $\begin{array}{c}\text { Tỉ lệ } \\
\text { \% }\end{array}$ \\
\hline \multicolumn{3}{|c|}{ Tuân hoàn trước } \\
\hline Động mạch cảnh trong & 10 & 21,27 \\
\hline Động mạch não giữa & 13 & 27,66 \\
\hline Động mạch não trước & 3 & 6,39 \\
\hline Động mạch thông trước & 5 & 10,63 \\
\hline Động mạch thông sau & 3 & 6,39 \\
\hline \multicolumn{3}{|c|}{ Tuân hoàn sau } \\
\hline Động mạch thân nền & 7 & 14,89 \\
\hline $\begin{array}{c}\text { Động mạch đốt sống và các } \\
\text { nhánh bên }\end{array}$ & 6 & 12.77 \\
\hline Tống số & 47 & 100 \\
\hline
\end{tabular}

Nút mach: 17, phẫu thuật: 30

Hầu hểt vi trí của phình mach não nằm ở tuần hoàn trước $(72,34 \%)$; chỉ có $26,66 \%$ túi phình nằm ở tuần hoàn sau.

Bảng 4. Các biến chứng-di chứng điều trị

\begin{tabular}{|c|c|c|}
\hline Đặc điểm & Số lượng & Tỉ lệ \% \\
\hline Viêm màng não & 3 & 6,39 \\
\hline Giãn não thất & 7 & 14,89 \\
\hline Thiếu máu não & 13 & 27,66 \\
\hline Tứ vong & 2 & 4,25 \\
\hline
\end{tabular}

Bảng 5. Kêt quả điều trị đánh giá theo thang điểm $m R S$

\begin{tabular}{|c|c|c|c|c|}
\hline $\begin{array}{l}\text { Điếm } \\
\text { mRS }\end{array}$ & $\begin{array}{l}\text { Khi vào } \\
\text { viện (1) }\end{array}$ & $\begin{array}{l}\text { Ra viện } \\
\text { (2) }\end{array}$ & $\begin{array}{c}\text { Sau } 3 \\
\text { tháng (3) }\end{array}$ & $\mathbf{p}$ \\
\hline 0 & 4 & 6 & 9 & \multirow{3}{*}{$\begin{array}{c}\mathrm{P} 1-2= \\
0,13\end{array}$} \\
\hline 1 & 8 & 10 & 15 & \\
\hline 2 & 15 & 18 & 20 & \\
\hline
\end{tabular}

\begin{tabular}{|c|c|c|c|c|}
\hline 3 & 11 & 8 & 1 & P1-3= \\
\hline 4 & 4 & 3 & 0 & 0,029 \\
\hline 5 & 5 & 0 & 0 & P2-3= \\
\hline 6 & 0 & 2 & 0 & 0,08 \\
\hline Tống số & 47 & 47 & $45^{*}$ & \\
\hline
\end{tabular}

*Số lượng bệnh nhân khám lại sau 3 tháng là 45 bênh nhân vì có 2 bệnh nhân tử vong trong khi nằm viện.

\section{BÀN LUẬN}

Tỉ lệ mắc bệnh phình động mạch não thay đổi tuỳ theo chủng tộc, nghiên cứu về cộng đồng cho thây tỉ lệ mắc là 2,2/100.000 dân ở Trung Quốc, và $22,5 \mathrm{ca} / 100.000$ dân ở Phần Lan và Nhật. Tỉ lệ này ở các nước đông nam á được ước tính vào khoảng 9,1 ca/100.000 dân. Tỉ lệ chảy máu dưới màng nhện do võ̃ phình động mach não thay đổi từ 2-16 ca/100.000 dân, trong đó tỉ lệ gặp ở các nước có thu nhập trung bình như nước ta cao ít nhất gấp đôi so với các nước phát triển. Vì vậy, chảy máu dưới màng nhện do võ phình mạch là một vấn đề nghiêm trọng đối với cộng đồng dân cư gần 100 triệu dân như Việt nam.

Connolly và cộng sự đã nhận định rằng, tỉ lệ tử vong do võ phình động mạch nã̉o cao hơn so với con số ước lượng là 12\%-15\% [2]

Tuổi trung bình trong nhóm nghiên cứu của chúng tôi là $46,4 \pm 13,26$; tỉ lệ nam là $42,55 \%$, không có sự khác biệt có ý nghĩa thống kê so với nữ. Trong nghiên cứu gần đây của Etminan, tuổi thường gặp là 45-54, nữ có xu hướng hay gặp hơn nam gới [4].

Thời gian từ khi bị đột quy cho đến khi được chẩn đoán trong nghiên cứu của chúng tôi là 17h, đây là một bước tiến đáng kể về cả hiểu biết, kiến thức và thực hành cũng như khả năng sẵn có của các cơ sở y tế. Cần phải nhắc lại rằng nguy cơ võ lại của phình động mạch não cao nhất là ở thời điểm 24h đầu sau chảy máu [5].

Đau đầu là triệu chứng gặp ở tất cả các bệnh nhân trong nhóm nghiên cứu của chúng tôi. Đau đầu có thể là do tăng áp lực nội sọ hoặc là do tình trạng có máu trong dịch não tuỷ, gây phản ứng của màng cứng. Đau đâu cũng là triệu chứng thường gặp nhất ở hầu hết các báo cáo về chảy máu dưới nhện do võ phình mạch, và được mô tả là "cơn đau đầu tồi tệ nhất trong cuộc đời", chiếm đến $80 \%$ số bệnh nhân [6] Tiểp theo là tình trang buồn nôn, nôn, các biểu hiện của tăng áp lực nội sọ. Có $17,02 \%$ số trường hợp có thất ngôn. Connolly cho rằng còn có các triệu chứng khác như cổ cứng, sợ ánh sáng, mất tri giác...[2]

Hầu hết các bệnh nhân trong nhóm nghiên 
cứu của chúng tôi đến bệnh viện trong tình trạng điểm GCS 9-12 (75,46\%; $\mathrm{p}=0,037)$. Có 10,64\% số bệnh nhân có điểm GCS 14-15. Điểm GCS khi vào viện cũng được Connolly và cộng sự xác định là một trong các yếu tố tiên lượng kết cục điêu trị. Hầu hết các tác giả đều có chung một nhận định là khoảng $10 \%$ số bệnh nhân phình động mạch võ đã tử vong trước khi đến bệnh viện, ở nước ta do điều kiện nguồn lực của hệ thống y tế còn hạn chế, chúng tôi cho rằng tỉ lệ này còn có thể cao hơn nữa.

Tỉ lệ đa túi phình mạch não được ước lượng chiếm khoảng $20 \%$ tổng số các phình mạch não [7]. Trong nghiên cứu của chúng tôi, tỉ lệ này là 12, 7\%. Đa túi phình động mạch não vơ gây khó khăn trong việc chẩn đoán và điều trị, bởi không phải trường hợp nào cũng có thể xác định được túi phình võ̃. Điều này sẽ không cần đắt ra nếu bệnh nhân được can thiệp nội mạch, xử trí tất cả các túi phình, song nếu phẫu thuật là phương pháp điều trị, việc xác định túi phình võ̃ rất quan trọng bởi phầu thuật viên cần phải tiến hành xử lý nó trước khi xử lý các túi phình chưa võ khác. Đây là một trong những đặc thù ở các nước đang phát triển nói chung và ở nước ta nói riêng.

Phân độ Fisher cải tiến được sử dụng rộng rãi với mục đích tiên lượng nguy cơ co thắt mạch, một trong những nguyên nhân gây ra kết cục điểu trị xấu [2], trong đó phân độ càng cao, nguy cơ co thắt mạch càng lớn. Trong nghiên cứu của chúng tôi phần lớn bệnh nhân có độ Fisher 1 và 2 . Đây là một trong những tiến bộ lớn về hệ thống chăm sóc cộng đồng, sự phổ biến rộng rãi về kiến thức y tế cho người dân, điều đó khiến cho bệnh nhân đến bệnh viện sớm để có được chẩn đoán sớm.

Có nhiều hệ thống phân độ chảy máu dưới nhện với mục đích chẩn đoán và tiên lượng kết cục điều trị bệnh nhân phình động mạch não võ̃, trong đó phân độ của Fisher cải tiển được sử dụng rộng rãi nhất.

Về điều trị, nhóm bệnh nhân của chúng tôi được điều trị bằng phương pháp can thiệp nội mạch là 17 trường hợp và phấu thuật là 30 trường hợp. Tất cả các trường hợp phình mạch ở tuần hoàn sau đều được nút mạch; ở tuần hoàn trước, chúng tôi ưu tiên chỉ định phình động mạch cảnh đoạn mắt bằng phương pháp can thiệp nội mạch. Mặc dù vậy, nhóm bệnh nhân của chúng tôi được phẫu thuật nhiều hơn nút mạch. Với các phình động mạch vỡ, điều trị phẫu thuật không chỉ giải quyết được túi phình, mà còn giúp bơm rửa lấy bỏ máu ở khoang dưới nhện, giúp giảm nguy cơ co thắt sau mổ và từ đó cải thiện kết cục điều trị. Connolly và cộng sự tổng kết rằng, phẫu thuật nên được ưu tiên ở những bệnh nhân có máu tụ trong não với thể tích trên $50 \mathrm{~mL}$ và các phình ở động mạch não giữa; trong khi đó can thiệp nội mạch lại ưu thế hơn ở nhóm bệnh nhân cao tuổi (>70) có điểm lâm sàng (WFNS) tồi.

Liên quan đến phẫu thuật, chúng tôi có 3 trong số 30 trường hợp phẫu thuật có viêm màng não, chiếm tỉ lệ $10 \%$. Các yếu tố nguy cơ bao gồm tuổi cao, điểm GCS thấp trước mổ khiến cho thời gian hồi sức kéo dài, nguy cơ viêm phổi cao hơn.

Giãn não thất là một trong những biến chứng của chảy máu dưới màng nhện do võ phình mạch. Chúng tôi gặp ở cả bệnh nhân được phẫu thuật và can thiệp nội mạch, trong nghiên cứu của chúng tôi, tỉ lệ biến chứng này là $14,89 \%$, tương đương với tổng kết của Connolly $(15 \%)$ [2]. Giãn não thất được các tác giả chia thành hai nhóm: cấp tính và mạn tính. Các trường hợp giãn não thất cấp tính thường là do hậu quả của hiện tượng bít tắc lưu thông dịch não tuỷ do máu cục, trong khi đó giãn não thất mạn tính thường được cho là hậu quả của tình trạng giảm hấp thu ở các hạt màng nhện [5].

Nghiên cứu của chúng tôi có $4,25 \%$ số bệnh nhân tử vong, tỉ lệ này thấp hơn so với các tác giả khác $[3,4]$. Yao và cộng sự cho rằng phẫu thuật sớm sẽ làm giảm tî̀ lệ tử vong của bệnh nhân phình động mạch não vỡ [8].

Đánh giá chức năng và chất lượng sống của bệnh nhân ở các thời điểm khi vào viện, ra viện và̀ sau 3 tháng chúng tôi thây có sự cại thiện có ý nghĩa thống kê $(p=0,029)$. Tuy nhiên, sự cải thiện này chỉ rõ rệt ở thời điểm 3 tháng so với khi vào viện, các thời điểm còn lại mặc dù có xu hướng tốt (điểm mRS giảm dần) song không có ý nghĩa thống kê $(p<0,05)$. Kết quả này của chúng tôi là do hầu hết bệnh nhân đều có điểm Fisher thấp, nguy cơ co thắt mạch thấp vì vậy kết quả điêu trị tốt hơn.

\section{KẾT LUÂ̂N}

Qua nghiên cứu 47 bệnh nhân trong thời gian gần đây, chúng tôi rút ra một số kết luận sau: tuổi trung bình của nhóm nghiên cứu là 46 tuổi, $76,46 \%$ bệnh nhân có điểm GCS 9-13 khi vào viện; $12,77 \%$ số bn có đa túi phình và $72,34 \%$ số túi phình nằm ở phần trước đa giác Willis. Kết quả điêu trị tốt ở tháng thứ 3 so với trước mổ. Điều trị chảy máu dưới nhện do võ̃ phình động mạch võ̃ là một chủ đề rất phức tạp, mặc dù đã có rất nhiều hiểu biết và tiến bộ. 


\section{TÀI LIẸU THAM KHẢO}

1. Hemphill, J.C., 3rd, et al., Guidelines for the Management of Spontaneous Intracerebral Hemorrhage: A Guideline for Healthcare Professionals From the American Heart Association/American Stroke Association. Stroke, 2015. 46(7): p. 2032-60.

2. Connolly, E.S., Jr., et al., Guidelines for the management of aneurysmal subarachnoid hemorrhage: a guideline for healthcare professionals from the American Heart Association/american Stroke Association. Stroke, 2012. 43(6): p. 1711-37.

3. Frontera, J.A., et al., Prediction of symptomatic vasospasm after subarachnoid hemorrhage: the modified fisher scale. Neurosurgery, 2006. 59(1): p. 21-7; discussion 21-7.

4. Etminan, $\mathbf{N}_{\text {., }}$ et al., Worldwide Incidence of Aneurysmal Subarachnoid Hemorrhage According to Region, Time Period, Blood Pressure, and Smoking Prevalence in the Population: A Systematic Review and Meta-analysis. JAMA Neurol, 2019. 76(5): p. 588-597.

5. Katsuno, M., et al., Subarachnoid hemorrhage caused by ruptured posterior inferior cerebellar artery aneurysm arising from the extracranial portion of an anomalous vertebral artery. Neurol Med Chir (Tokyo), 2012. 52(7): p. 499-501.

6. Togha, M., et al., Warning signs and symptoms of subarachnoid hemorrhage. South Med J, 2009. 102(1): p. 21-4

7. Kaminogo, M., M. Yonekura, and S. Shibata, Incidence and outcome of multiple intracranial aneurysms in a defined population. Stroke, 2003. 34(1): p. 16-21.

8. Yao, Z, et al., Timing of surgery for aneurysmal subarachnoid hemorrhage: A systematic review and meta-analysis. Int J Surg, 2017. 48: p. 266-274.

\section{SỰ BộC Lộ THỤ THỂ ANDROGEN VÀ ESTROGEN TRONG UNG THƯ BIỂU MÔ TUYẾN VÚ XÂM NHẬP}

\section{TÓM TẮT}

Thu thể androgen (AR) liên quan tới môt yếu tố phiên mã kiểm soát các gen đặc hiệu liên quan đến các quá trình tế bào khác nhau, đôi khi ngước lai: nó có thể kích thích hoặc ức chế cả tăng sinh tế bào và apoptosis, tùy thuộc vào các con đường tín hiêuu đồng thời được hoạt hóa. Mục tiêu: Nhận xét một số mối liên quan giữa sự bộc lộ $A R, E R$ với typ phân tử, NPI, nhóm nguy cơ và giai đoạn sau mổ của ung thư vú. Đối tượng và phương pháp nghiên cứu: Mẫu mô u čủa 94 bệnh nhân ung thư vú được nhuộm hóa mô miễn dịch với dấu ấn $A R$, ER để xác định kiểu hình miê̂n dịch và đánh giá mối liên quan với một số đặc điểm GPB. Kết quả nghiên cứu: Ở typ phân tử HER2, nhóm AR-ER- chiếm tỷ lệ cao nhất $(55,9 \%)$ và ung thư vú dang đáy, kiểu hình $A R+E R-$ chiếm tỷ lê phổ biến nhất là $52,9 \%$. AR-ER- chiếm tỷ lệ cao nhất ở ung thư vú nguy cơ xấu (58,8\%). Ung thư vú giai đoan I nhóm $A R-E R+$ và $A R+E R+$ đều chiếm tỷ lệ cao hơn giai đoạn III (lần lượt là 40,0 vs $13,3 \%$ và 29,8 vs 21,5\%). Kết luân: Kiểu hình miễn dịch AR-ERthường kết hợp với các đặc trưng GPB xấu nhất.

Tư khóa: Thu thể androgen, Thu thể estrogen, Ung thư vú.

\section{SUMMARY \\ EXPRESSION OF ANDROGEN AND ESTROGEN RECEPTORS IN INVASIVE}

\footnotetext{
*Bênh viên $K$

Chịu trách nhiệm chính: Nguyễn Văn Chủ

Email: chunv.nch@gmail.com

Ngày nhận bài: 1.2.2021

Ngày phản biên khoa hoc: 16.3.2021

Ngày duyệt bài: 23.3.2021
}

Nguyễn Văn Chủ*

\section{BREAST CARCINOMA}

Androgen receptor (AR) links a transcription factor that controls specific genes involved in different, sometimes opposite, cellular processes: it can stimulate or suppress both cell proliferation and apoptosis, depending on the concurrent signaling pathways activated. Purpose: To Comment on some relationships between the expression of $A R, E R$ and molecular type, NPI, risk group and postoperative stage of breast cancer. Methods: Tumor samples of 94 breast cancer patients were stained with AR and ER IHC markers to determine the immunophenotype and to assess association with some pathological features. Results: In the HER2 molecular type, the AR-ER- group was accounted for the highest proportion (55.9\%) and in the breast cancer with basal type, phenotype AR+ ER- was accounted for the most common rate of $52.9 \%$. AR-ER- accounts for the highest incidence of bad risk breast cancer (58.8\%). Both AR-ER+ and AR+ ER+ stage I breast cancer were accounted for a higher rate than stage III (40.0 vs $13.3 \%$ and 29.8 vs $21.5 \%$, respectively). Conclusion: The AR-ER- immunophenotype is often associated with the worst pathological characteristics.

Key words: Androgen receptor, Estrogen receptor, Breast cancer.

\section{I. ĐặT VẤN ĐỀ}

Thụ thể androgen (AR) là một thụ thể nội tiết tố steroid thuộc đến họ thụ thể nhân cùng với estrogen (ER), glucocorticoid, progesterone (PR) và thu thể mineralcorticoid. Nó liên quan tới một yếu tố phiên mã kiểm soát các gen đặc hiệu liển quan đến các quá trình tế bào khác nhau, đôi khi ngược lại: nó có thể kích thích hoặc ức chế cả 